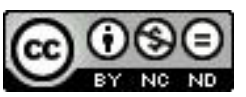

\title{
Influência dos Padrões de Interação Didática no Desenvolvimento da Aprendizagem Matemática: análise de uma atividade exploratório-investigativa sobre sequências
}

\author{
Influence of Didactical Interaction Patterns into the \\ Development of Mathematics Learning: an analysis of \\ an exploratory-investigative activity about sequences
}

\author{
Adriana Assis* \\ Cristina Frade** \\ Juan D. Godino***
}

\begin{abstract}
Resumo
Neste artigo exploramos as configurações didáticas e, mais especificamente, os padrões de interação estabelecidos entre professoras e alunos em uma atividade exploratórioinvestigativa de Matemática. Essa atividade foi implementada em uma turma do sétimo ano do Ensino Fundamental (alunos de aproximadamente 12 anos), visando melhor compreender a emergência dos padrões de interação e seus efeitos sobre o desenvolvimento da aprendizagem. Identificamos as configurações didáticas, utilizando um modelo teórico-metodológico concebido para descrever e interpretar os processos

\footnotetext{
"Doutora em Educação pela Universidade Federal de Minas Gerais (UFMG). Professora Adjunta do Departamento de Educação a Distância, Universidade Federal dos Vales do Jequitinhonha e Mucuri (UFVJM), Diamantina, MG, Brasil. Endereço para correspondência: Campus JK, Rodovia MGT 367, km 583, 5000, Alto da Jacuba, CEP: 39100-000, Diamantina, MG, Brasil. E-mail: adriana.assis@ufvjm.edu.br.

*** Doutora em Educação pela Universidade Federal de Minas Gerais (UFMG). Professora da Faculdade de Educação, Universidade Federal de Minas Gerais (UFMG), Belo Horizonte, MG, Brasil. Endereço para correspondência: Av. Antônio Carlos, 6627, Pampulha, CEP: 31270-901, Belo Horizonte, MG, Brasil. E-mail: cristinafrade@ufmg.br.

*** Doutor em Matemática pela Universidade de Granada (UGR), Granada, Espanha. Catedrático de Didática da Matemática, Departamento de Didática da Matemática, Universidade de Granada (UGR), Granada, Espanha. Dirección postal: Facultad de Educación, Campus de Cartuja, 18071, Granada, España. E-mail: jgodino@ugr.es.
} 
interativos em sala de aula. Como conclusão, ressaltamos a necessidade da gestão entre as distintas configurações, e a consequente cooperação produtiva (sinergia) entre os diferentes padrões de interação, para estabilizar a negociação de significados e possibilitar o desenvolvimento da aprendizagem dos alunos.

Palavras-chave: Enfoque Ontossemiótico. Configurações Didáticas. Padrões de interação. Atividades exploratório-investigativas. Sequências.

\begin{abstract}
The aim of this paper is to explore the didactic configurations and, more specifically, the patterns of interaction established between teachers and students during an exploratoryinvestigative mathematical activity. This activity was implemented in a seventh grade class (students approximately 12 years old) and aimed to contribute to understanding regarding the emergence of the patterns of interactions and their effects on the development of learning. We identified the didactic configurations using a theoreticalmethodological model designed to describe and interpret the interactive processes in the classroom. In conclusion, we emphasize the need for management between the distinct configurations, and the consequent productive cooperation (synergy) between the different interaction patterns, to stabilize the negotiation of meanings and enable the development of students' learning.
\end{abstract}

Keywords: Onto-semiotic Approach. Didactic Configurations. Patterns of interaction. Exploratory-investigative activities. Sequences.

\title{
1 Introdução
}

Em se tratando de propostas curriculares ou de formação de professores de Matemática, o trabalho com as investigações matemáticas é frequentemente apresentado como experiência fundamental tanto para a aprendizagem matemática dos alunos quanto para o desenvolvimento profissional do professor. A opção por esse tipo de atividade fundamenta-se na crença de que ambientes dessa natureza podem configurar um contexto rico e profícuo para o partilhamento e negociação de significados (BRUNER, 2002) entre os próprios alunos, e entre os alunos e o professor.

Atividades de investigação oferecem, potencialmente, a possibilidade de os alunos vivenciarem experiências matemáticas. No entanto, para que essa atitude investigativa possa se desenvolver, recomenda-se que o professor centre a aula na atividade dos alunos, em suas ideias e em sua pesquisa, e mantenha uma postura questionadora gerenciando o grau de apoio a dar aos alunos 
(PONTE; FONSECA; BRUNHEIRA, 1999), de preferência o menor possível. Contudo, a cultura da sala de aula não se altera de uma hora para outra, já que diversos são os fatores que podem influenciar a transição de uma dinâmica clássica para uma dinâmica investigativa. Alguns desses fatores estão ligados a normas e metanormas ${ }^{1}$ relacionadas ao papel do professor e da escola (ASSIS; GODINO; FRADE, 2012).

Diante desse cenário, e entendendo que a compreensão dos processos interativos em sala de aula é fundamental para redimensionar as práticas pedagógicas, propomos, neste artigo, explorar as configurações didáticas (GODINO; CONTRERAS; FONT, 2006) e, mais especificamente, os padrões de interação estabelecidos entre professoras e alunos em uma atividade exploratório-investigativa de Matemática, visando melhor compreender a emergência desses padrões e seus efeitos sobre o desenvolvimento da aprendizagem. Para tal, analisamos uma tarefa exploratório-investigativa implementada em uma turma do sétimo ano do Ensino Fundamental (alunos de aproximadamente 12 anos) de uma escola pública situada na região urbana de Belo Horizonte (MG).

Na primeira parte do artigo, explicitamos os construtos teóricos adotados, o problema de pesquisa e contextualizamos a tarefa implementada. Em seguida, analisamos e discutimos as trajetórias e interações didáticas estabelecidas pelas professoras e alunos no desenvolvimento da atividade, utilizando como modelo teórico-metodológico o $3^{\circ}$ nível de análise proposto pelo Enfoque Ontossemiótico do Conhecimento Matemático (EOS) (FONT; PLANAS; GODINO, 2010). Também, identificamos os padrões de interação suscitados (GODINO; LLINARES, 2000; MENEZES, 2005) indispensáveis à inferência dos atos e processos de significação mobilizados. Como conclusão, ressaltamos a necessidade da gestão entre as distintas configurações, e a consequente cooperação produtiva (sinergia) entre os diferentes padrões de interação, para estabilizar a negociação de significados e possibilitar o desenvolvimento da aprendizagem dos alunos.

\footnotetext{
${ }^{1}$ Tomando-se o contexto da sala de aula, a noção de normas refere-se ao cumprimento de papéis que regem as interações entre professor e alunos e, em geral, às convenções estabelecidas de maneira histórica sobre como se comunicar e como reagir ante as intervenções dos outros (PLANAS; IRANZO, 2009). Considerando que as normas são negociadas dentro da sala de aula, e, portanto, são objeto de interpretação, valoração e reflexão pelos agentes envolvidos, considera-se que professor e os alunos mobilizam conhecimentos que dizem respeito a conteúdos de Matemática, mas também conhecimentos sobre Matemática, sobre sua utilização, sobre ensino e aprendizagem (particularmente de Matemática) e, dentre outros, sobre a consciência que tem o sujeito do próprio conhecimento. As normas, de segunda ordem, relativas a esse metaconhecimento, D'Amore, Font e Godino (2007) denominam metanormas.
} 


\section{Marco teórico}

O EOS propõe cinco níveis ou tipos de análise didática: 1) Identificação de práticas matemáticas; 2) Elaboração das configurações de objetos e processos matemáticos; 3) Análise das trajetórias e interações didáticas; 4) Identificação do sistema de normas e metanormas; 5) Valoração da idoneidade didática do processo de ensino e aprendizagem (FONT; PLANAS; GODINO, 2010).

Apesar de considerarmos que uma análise didática precisa descrever e explicar a aprendizagem, bem como a forma como se dá sua produção, em termos dos diversos níveis de análise do EOS, neste artigo centramos a atenção no nível 3 - as trajetórias didáticas implementadas e os padrões de interação estabelecidos. Essa opção deve-se ao fato de que a aplicação dos demais níveis de análise do EOS requer uma ampliação excessiva da extensão deste artigo e de seus objetivos. De todo modo, consideramos que as noções teóricas próprias do nível 3 (configuração didática, trajetória didática e padrão de interação) são suficientes e adequadas para desvelar fenômenos didáticos que, com frequência, passam desapercebidos, bem como proporcionam insigths significativos sobre o papel das interações em sala de aula para compreender os processos de aprendizagem dos alunos e propor critérios para sua melhora progressiva.

\subsection{Configurações didáticas}

Uma configuração didática é um intervalo ou segmento de atividade didática (ensino e aprendizagem) que se distribui entre os momentos de início e término de uma tarefa ou situação-problema. Inclui, portanto, as ações dos alunos e do professor, assim como os meios usados para abordar o estudo conjunto da referida tarefa.

Uma configuração didática (Figura 1) é composta por uma configuração epistêmica - uma tarefa, as ações requeridas para sua solução, linguagens, definições, proposições, procedimentos e argumentações, as quais podem estar a cargo do professor, dos alunos ou distribuídas entre ambos - uma configuração instrucional, onde encontra-se uma configuração docente e outra discente em interação, e uma configuração cognitivo-afetiva.

Uma sequência de configurações didáticas orientada à aprendizagem de um tipo de situação-problema (ou de um conteúdo específico) constitui uma trajetória didática (Figura 1). Como é descrito em Godino, Contreras e Font (2006), as trajetórias didáticas - que são compostas por sub-trajetórias 
epistêmicas, docentes, discentes, mediacionais e interacionais - condicionam o desenvolvimento das trajetórias cognitivas dos sujeitos envolvidos nas práticas sociais. Essas trajetórias, por sua vez, descrevem a aprendizagem conquistada pelos alunos, sendo sua otimização o principal objetivo do processo educativo.

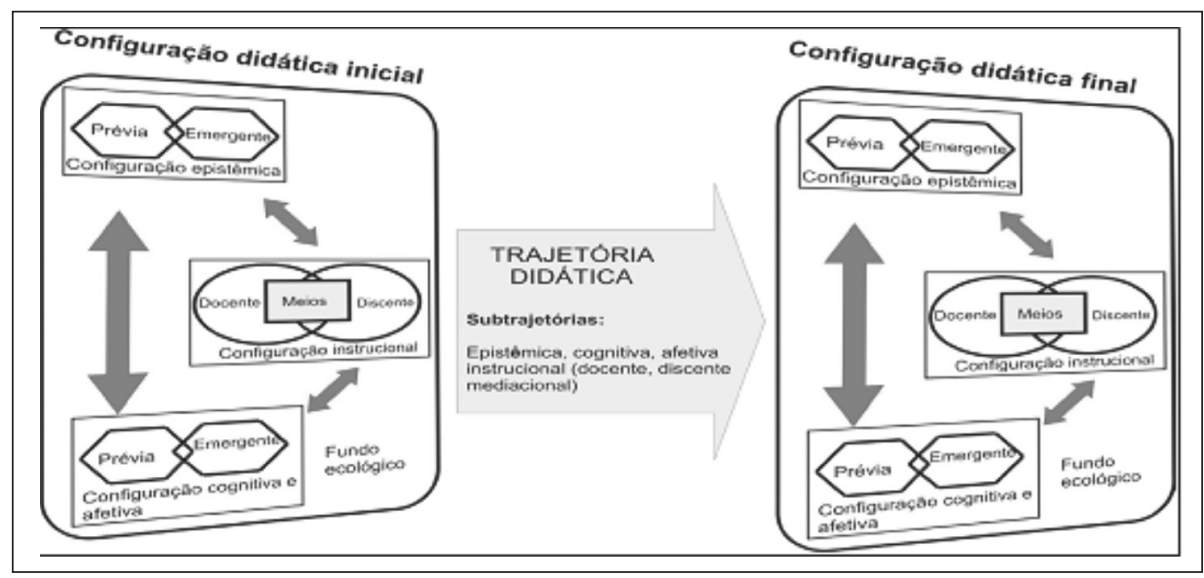

Figura 1 - Interações didáticas

Fonte: Godino, Batanero e Font (2008, p. 21)

Godino, Contreras e Font (2006) descrevem, utilizando como critério as interações estabelecidas, quatro tipos de configurações didáticas teóricas de referência: configurações magistral, a-didática, dialógica e pessoal.

A configuração didática magistral refere-se à maneira clássica de ensinar Matemática: apresentação do conteúdo pelo professor, seguida de exercícios de aplicação dos conhecimentos e saberes apresentados.

Uma configuração didática é considerada a-didática quando o aluno (ou um grupo de alunos em trabalho colaborativo), em concordância com o professor, assume a responsabilidade do trabalho matemático - exploração de possíveis técnicas de solução, formulação, comunicação e validação - e se engaja em um processo de busca autônoma, sem receber nenhum tipo de apoio por parte do professor.

Uma variação intermediária desses dois tipos de configuração é definida quando o professor se encarrega da formulação e validação do problema, enquanto os alunos se responsabilizam pela exploração. A partir do diálogo entre o professor e os alunos, estes têm a oportunidade de assumir a tarefa, familiarizarem com ela e, possivelmente, esboçar alguma estratégia de solução. Nesse caso, a configuração didática é chamada dialógica. 
A noção de configuração didática pessoal é introduzida em Godino, Contreras e Font (2006) para analisar segmentos instrucionais mais amplos do que os segmentos propostos para análise no presente artigo, e referem-se a momentos em que o estudo é realizado de maneira individual pelo aluno e normalmente fora da sala de aula (estudo pessoal em casa, biblioteca, etc.). Tendo em vista que neste trabalho analisamos episódios ocorridos em sala de aula, utilizamos como referência apenas as configurações a-didática, dialógica e magistral.

Em Godino, Contreras e Font (2006) considera-se que quando muda a tarefa (ou problema abordado), muda-se a configuração didática. Por outro lado, esses autores afirmam que uma mesma configuração didática empírica pode reunir traços/características de dois ou mais tipos de configurações didáticas teóricas. Em outras palavras, pode acontecer de uma mesma configuração didática apresentar mais de uma classificação ao ser comparada com as configurações teóricas de referência.

De fato, durante a realização de uma tarefa podem-se implementar diferentes padrões de interação (trabalho autônomo dos alunos, explicações magistrais, diálogo e cooperação entre alunos e professor etc.). Cada subintervalo de atividade em que acontece um de tais padrões é denominado, neste trabalho, por subconfiguração didática, noção que permite uma análise mais pormenorizada das configurações e trajetórias didáticas, tornando possível revelar a sinergia (cooperação produtiva) entre os distintos padrões de interação.

\subsection{Padrões de interação}

Voigt (1995) define padrões de interação como regularidades constituídas nas interações entre o professor e os alunos ${ }^{2}$. Para Godino e Llinares (2000, p. 9) "quando os participantes constituem uma regularidade que um observador descreve como um padrão de interação, essa regularidade está estabilizando um processo frágil de negociação de significados”. Esses autores destacam os seguintes padrões de interação tratados na investigação em Educação Matemática:

Padrão extrativo (VOIGT, 1985): o professor propõe uma tarefa ambígua e os alunos são estimulados a explorá-la e analisá-la espontaneamente.

\footnotetext{
${ }^{2}$ Neste trabalho centramo-nos apenas nos padrões de interação assumidos pelas professoras e alunos. Fizemos uma opção por dedicarmos mais à atuação do professor e, portanto, não analisamos os padrões emergentes das interações dos alunos entre si.
} 
Em seguida, o professor conduz uma discussão extraindo fragmentos de conhecimentos que estão associados a pequenos passos no raciocínio dos alunos.

Padrão de discussão (VOIGT, 1985): o professor pede a um aluno que o informe sobre o trabalho desenvolvido pelo grupo. Em seguida, contribui com as explicações dos alunos fazendo perguntas adicionais, observações e reformulações de maneira que uma explicação ou solução conjunta emerja e seja tomada como válida. Por fim, o professor pergunta se há outros modos de solução e inicia, novamente, o ciclo de discussão.

Padrão do funil (VOIGT, 1985; BAUERSFELD, 1988): o professor, diante da dificuldade dos alunos de resolver um problema, propõe questões mais fáceis relacionadas ao problema e cuja solução possa conduzir à sua resolução.

Padrão de focalização (WOOD, 1994): é uma variante do anterior, porém, nesse caso, o professor propõe uma série de perguntas com o objetivo de estreitar o foco da atenção dos alunos a um aspecto específico do problema, tentando fazer com que eles ultrapassem as dificuldades. Feito isso, o professor deixa os alunos continuarem o trabalho de forma autônoma.

Padrão de matematização direta (VOIGT, 1996): o professor propõe aos alunos uma tarefa suficientemente aberta para permitir diferentes interpretações e, consequentemente, diferentes abordagens matemáticas. Em seguida, reduz o número de possibilidades de interpretação, conduzindo os alunos para um determinado modo de interpretar a tarefa, direcionando-os a seguir suas próprias abordagens.

Sierpinska (1996) identifica também os padrões é isso e tem certeza?, que Godino e Llinares (2000) denominam, respectivamente, como padrões afirmativo e interrogativo. Esses padrões referem-se às interações em que o professor, no primeiro caso, valida a afirmação/solução do aluno dizendo que está correto (ou que não está correto) e, no segundo caso, convida o aluno a verificar sua afirmação/solução (mesmo no caso de estar correta).

Menezes (2005) destaca, ainda, o padrão de recitação. Aqui, o professor toma a iniciativa de explicar a matéria. Em seguida, os alunos respondem as perguntas propostas e as respostas são avaliadas pelo professor. Essas aulas decorrem, regra geral, da realização de tarefas rotineiras.

\subsection{Atividades exploratório-investigativas}

A aprendizagem baseada na investigação (inquiry learning) é uma abordagem originada de práticas de investigação científica e enfatiza o processo 
de propor questões ou problemas relevantes, produzir e analisar dados e construir argumentos baseados em evidências (HMELO-SILVER; DUNCAN; CHINN, 2007).

Utilizando o termo investigações matemáticas para denominar uma abordagem investigativa que se insere no que Ernest (1996) denomina pedagogia orientada para investigação (inquiry-oriented pedagogy) ${ }^{3}$, Ponte, Fonseca e Brunheira (1999) diferenciam as investigações da resolução de problemas da seguinte maneira:

$\mathrm{Na}$ resolução de problemas, tal como é entendida inicialmente, o objetivo é encontrar o caminho para atingir um ponto não imediatamente acessível. É um processo convergente. Numa investigação matemática, o objetivo é explorar todos os caminhos que surgem como interessantes, a partir de dada situação. É um processo divergente. Sabese qual é o ponto de partida, mas não se sabe qual será o ponto de chegada (PONTE; FONSECA; BRUNHEIRA, 1999, p. 94-95).

Banchi e Bell (2008) argumentam que a aprendizagem baseada na investigação pode ser desenvolvida em quatro níveis (Quadro 1):

\begin{tabular}{|l|c|c|c|}
\hline Níveis de investigação & Questão & Procedimento & Solução \\
\hline $\begin{array}{l}\text { 1-Investigação de confirmação } \\
\text { Os alunos confirmam uma proposição, através de uma } \\
\text { atividade, quando os resultados são conhecidos } \\
\text { antecipadamente. }\end{array}$ & $\checkmark$ & $\checkmark$ & \\
\hline $\begin{array}{l}\text { 2-Investigação estruturada } \\
\text { Os alunos investigam uma pergunta apresentada pelo } \\
\text { professor, através de procedimentos prescritos. }\end{array}$ & $\checkmark$ & $\checkmark$ & \\
\hline $\begin{array}{l}\text { 3- Investigação guiada } \\
\text { Os alunos investigam uma pergunta apresentada pelo } \\
\text { professor, usando procedimentos desenhados/selecionados } \\
\text { pelos alunos. }\end{array}$ & $\checkmark$ & & \\
\hline $\begin{array}{l}\text { 4-Investigação aberta } \\
\text { Os alunos investigam questões que são formuladas por } \\
\text { eles próprios, a partir de procedimentos } \\
\text { desenhados/selecionados pelos alunos. }\end{array}$ & & & \\
\hline
\end{tabular}

Quadro 1 - Os quatro níveis de investigação e a informação dada ao aluno em cada um Fonte: Banchi e Bell (2008, p. 27)

\footnotetext{
${ }^{3}$ Descoberta guiada, resolução de problemas e abordagem investigativa são métodos que se fundamentam na investigação para o ensino de Matemática, constituindo o que Ernest (1996) chama de uma pedagogia orientada para investigação.
} 
Neste estudo utilizamos a expressão atividades exploratório-investigativas para sinalizar o tipo de tarefa em que os alunos se dedicam tanto à exploração quanto à investigação matemática. Acreditamos que a expressão exploratórioinvestigativas é mais apropriada para descrever o que ocorre com alunos do Ensino Fundamental, que, pela primeira vez, se defrontam com esse tipo de atividade.

\section{Problema e metodologia}

O foco de nossa investigação incide na realização de atividades exploratório-investigativas implementadas em um contexto de aulas de Matemática em uma turma de 15 alunos (6 meninas e 9 meninos) do sétimo ano do Ensino Fundamental (aproximadamente 12 anos) de uma escola pública situada na região urbana de Belo Horizonte (MG). A finalidade dessa pesquisa foi introduzir esses alunos, acostumados a uma dinâmica clássica de aulas, em uma modalidade sociointeracionista ${ }^{4}$ de aprendizagem baseada na exploração, investigação e trabalho cooperativo.

Tendo como cenário as aulas exploratório-investigativas, procuramos, neste artigo, oferecer uma resposta à seguinte questão: como articular os diferentes padrões de interação, mobilizados por professoras e alunos, para otimizar a aprendizagem matemática?

Atendendo às características da natureza desse estudo, adotamos uma metodologia qualitativa e interpretativa (BOGDAN; BIKLEN, 1994). Para analisar as interações didáticas, partimos da transcrição ${ }^{5}$, gerada a partir de gravações em áudio (alguns trechos também em vídeo), de uma atividade exploratório-investigativa sobre sequências (Figura 2). Utilizamos como modelo teórico-metodológico o $3^{\circ}$ nível de análise, proposto pelo EOS (FONT; PLANAS; GODINO, 2010), e a identificação de padrões de interação como descritos por Godino e Llinares (2000) e Menezes (2005).

Ao longo do ano de 2010, foram implementadas nove atividades exploratório-investigativas que envolveram temas de Aritmética, de medidas, de Geometria e de Álgebra. O tempo de aula dedicado à implementação de cada

\footnotetext{
${ }^{4}$ Por sociointeracionismo estamos nos referindo à perspectiva de Vygotsky e colaboradores, que postula que o psiquismo humano é concebido como uma construção social, "resultado do processo de interiorização das funções psíquicas desenvolvidas ao longo da história social dos homens. A interiorização ocorre numa rede complexa de inter-relações que articulam a atividade social dos indivíduos" (PINO, 1991, p. 32, grifos do autor).

${ }^{5}$ As falas transcritas foram numeradas de 1 a 827 . Quando nos referimos a esse extrato colocamos o número que indica o turno entre colchetes.
} 
uma dessas atividades foi de 1 hora e 40 minutos (aulas geminadas de 50 minutos). A tarefa, aqui analisada (Figura 2), trata da sétima atividade implementada, e foi selecionada para análise porque os alunos, nesse momento, já haviam internalizado as normas e metanormas subjacentes ao trabalho com atividades exploratório-investigativas ${ }^{6}$ (ASSIS; GODINO; FRADE, 2012), embora se encontrassem, ainda, em uma fase de transição entre a aula clássica e o trabalho de investigação.

A atividade foi realizada por duas professoras: a primeira autora do presente artigo e a professora da turma, denominadas aqui, respectivamente, por Prof 1 e Prof 2. A turma em questão apresentava-se distribuída em mesas hexagonais dispostas pela sala e se organizou livremente em 4 grupos. Analisamos, no entanto, apenas o trabalho realizado por um grupo constituído de quatro meninos denominados, hipoteticamente, por Marcelo, Paulo, Vanderlei e Valter. Escolhemos esse grupo pelo fato de, apesar de apresentar dificuldades em Matemática, mostrar-se bastante motivado e comprometido com a atividade, demonstrando persistência no trabalho com a mesma, ainda quando não conseguia progredir satisfatoriamente.

\section{ATIVIDADE 1}

Observe a sequência de figuras abaixo:

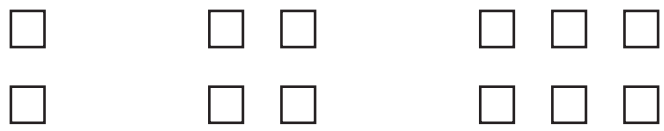

a) Qual a próxima figura da sequência? Desenhe.

b) E a seguinte? Desenhe.

c) Escreva a regra de formação dessa sequência.

d) Observando a sequência, quantos quadradinhos tem cada figura?

e) Quantos quadradinhos tem a $6^{\mathrm{a}}$ figura da sequência?

f) E a $7^{\text {a }}$ ? E a $8^{\text {a }}$ ? E a $15^{\text {ar }}$ ?

\footnotetext{
${ }^{6}$ Por exemplo, a metanorma de que o professor não deve aportar todas as informações nem dar a solução direta para o problema (norma metainstrucional), principalmente quando o grupo se encontra em um momento crítico/chave da resolução da tarefa. O grupo, nesse momento, ao contrário das primeiras oficinas, já consegue tomar a iniciativa de buscar resolver a tarefa sem requisitar ajuda constante por parte das professoras e sem se ressentir com o fato de elas não darem respostas prontas.
} 


\section{$\underline{\text { ATIVIDADE } 2}$}

Observe as figuras abaixo:

a) Continuando a sequência acima, qual a próxima figura? Desenhe.

b) E a seguinte? Desenhe.

c) Quantos pontos tem a $5^{\mathrm{a}}$ figura?

d) E a $6^{\text {a }}$ figura?

e) Quantos pontos tem uma figura numa posição qualquer?

\section{$\underline{\text { ATIVIDADE } 3}$}

Observe a sequência:

a) Qual a próxima figura dessa sequência? Desenhe.

b) E a seguinte? Desenhe.

c) Como cada figura se transforma na seguinte?

d) Quantos pontos tem a $6^{a}$ figura?

e) Qual a $10^{\mathrm{a}}$ figura? Ela tem quantos pontos?

f) Quanto pontos tem uma figura numa posição qualquer?

Figura 2 - Tarefa exploratório investigativa implementada Fonte: Souza e Diniz (2003, p. 24; 27; 29)

Com essa tarefa, pretendíamos dar oportunidade aos alunos de, a partir da determinação do próximo termo, e em seguida, de termos mais distantes, construir uma expressão algébrica para cada sequência dada.

A disposição e o número de bolinhas de uma determinada figura da sequência admite apenas uma resposta correta. No entanto, a regra de formação da sequência admite várias possibilidades, o que propicia oportunidades para a exploração e a investigação matemática (ainda que em um formato inicial). No decorrer da atividade, esperava-se que os alunos percebessem que as operações aritméticas não seriam suficientes para resolver a tarefa e sentissem a necessidade de utilizar palavras e, posteriormente, símbolos para representar 
as variáveis expondo-as na forma de uma expressão matemática.

As atividades 2 e 3 da tarefa possuem, no nosso entender, maior grau de dificuldade na medida em que exigem que os alunos relacionem o número de bolinhas de cada figura com a respectiva posição que ocupam na sequência. Esperava-se, portanto, que a ideia de relação/variação entre grandezas também fosse explorada/desenvolvida pelos alunos a partir dessas atividades.

\section{Identificação dos tipos de configurações e padrões de interação}

As professoras envolvidas no trabalho combinaram, devido à natureza das atividades investigativas, que tentariam dar aos alunos a oportunidade de desenvolverem a atividade de maneira mais autônoma possível. O que ocorreu, no entanto, foi que os alunos demandaram, frequentemente, apoio por parte das professoras para conseguirem progredir nas atividades. Sendo assim, as professoras optaram, nesses momentos, predominantemente, pelo padrão de focalização. O padrão recitativo foi adotado apenas por Prof 1 (a pesquisadora), com o intuito de que os alunos conseguissem desenvolver a tarefa até o final (nesse momento, assumindo mais o seu papel de professora).

Foram identificadas três configurações didáticas (CD) - que referemse, respectivamente, às atividades 1,2 e 3 da tarefa - e dezesseis subconfigurações didáticas ( $\mathrm{SCD}$ ) delimitadas por momentos em que ocorreram mudanças nos padrões de interação. O Quadro 2 permite a visualização da trajetória didática implementada na tarefa exploratório-investigativa analisada, bem como apresenta a distribuição (e classificação) das configurações e subconfigurações didáticas, levando-se em conta a atividade a que se referem. 


\begin{tabular}{|c|c|c|c|c|}
\hline \multirow{2}{*}{\multicolumn{2}{|c|}{$\begin{array}{c}\text { Tarefa } \\
\text { exploratório-investigativa } 7\end{array}$}} & \multicolumn{3}{|c|}{ Tipos de Configuração Didática } \\
\hline & & \multirow{2}{*}{$\frac{\text { a-didática }}{\mathrm{x}}$} & \multirow{2}{*}{ dialógica } & \multirow{2}{*}{ Magistral } \\
\hline \multirow{5}{*}{ Atividade 1} & SCD1 & & & \\
\hline & SCD2 & & $\mathrm{x}$ & \\
\hline & SCD3 & $\mathrm{x}$ & & \\
\hline & SCD4 & & $\mathrm{x}$ & \\
\hline & SCD5 & & & $\mathrm{x}$ \\
\hline \multirow{8}{*}{$\begin{array}{c}\text { CD2 } \\
\text { Atividade } 2\end{array}$} & SCD6 & $\mathrm{x}$ & & \\
\hline & SCD7 & & $\mathrm{x}$ & \\
\hline & SCD8 & $\mathrm{x}$ & & \\
\hline & SCD9 & & $\mathrm{x}$ & $\mathrm{x}$ \\
\hline & SCD10 & & & $\mathrm{x}$ \\
\hline & SCD11 & $\mathrm{x}$ & & \\
\hline & SCD12 & & & $\mathrm{x}$ \\
\hline & SCD13 & $\mathrm{x}$ & & \\
\hline \multirow[b]{3}{*}{ Atividade 3} & SCD14 & $\mathrm{x}$ & & \\
\hline & SCD15 & & $\mathrm{x}$ & \\
\hline & SCD16 & $\mathrm{x}$ & & \\
\hline \multicolumn{2}{|c|}{ TOTAL } & 8 & 5 & 3 \\
\hline
\end{tabular}

Quadro 2 - Trajetória didática implementada na tarefa exploratório-investigativa 7 Fonte: dados da pesquisa

A seguir, apresentamos momentos, da CD2, que consideramos representativos para exemplificar os tipos de configurações (Quadro 2) e padrões de interação identificados.

No momento inicial, foram distribuídas folhas de atividades individuais (Figura 2) e um saquinho contendo tampinhas de garrafa pet para cada um dos grupos. Foi pedido aos grupos que representassem cada uma das sequências utilizando as tampinhas e que buscassem encontrar uma forma de representar uma figura em uma posição qualquer (o enésimo termo). No início da CD2, o grupo analisado não requisitou a ajuda das professoras e não apresentou dificuldades com o procedimento de generalização próxima ${ }^{7}$ (SCD6

\footnotetext{
${ }^{7}$ A generalização próxima, refere-se ao processo de determinar, em uma sequência, os próximos termos (pode ser obtida continuando a desenhar ou escrever a sequência até chegar ao termo pedido. Já a generalização distante refere-se ao processo de determinar um termo mais afastado da sequência (o objetivo seria o de fazer os alunos, diante da dificuldade, sentirem necessidade de determinar uma regra geral) (STACEY, 1989).
} 
subconfiguração a-didática). Contudo, não conseguiu obter, apesar de ter realizado exaustivas explorações ${ }^{8}$, uma regra geral para a sequência. Esse fato levou Prof 2 a intervir na discussão do grupo (SCD7), estreitando as possibilidades de resolução (subconfiguração dialógica), e a sugerir aos alunos que pensassem em uma figura geométrica [255]. Prof 2 tentou, com essa mediação, fazer com que os alunos ultrapassassem as dificuldades, mas deixou-os continuarem seu trabalho de forma autônoma (padrão de focalização). A intervenção do aluno Paulo [259], no entanto, muito provavelmente pela justificação e pelo tom de voz veemente registrado em áudio, fez com que o grupo não se dedicasse, nesse momento, a explorar a sugestão da professora, conforme mostrado no extrato abaixo:

Prof 2: Vocês chegaram a alguma conclusão? [249]

Paulo: Não, a gente entendeu o quê que é. Só não tem como explicar a regra... [250]

Prof 2: Pensem em uma figura geométrica envolvida... [255] Marcelo: Quadrado. [256]

Paulo: Não. Quadrado não tem uma bolinha, não né fio! [257]

Marcelo: inaudível [258]

Paulo: Então não é um quadrado. É igual todo mundo tem um tênis, menos eu. Então não é todo mundo mais! Hã! [259]

Segue-se um momento (SCD8) em que os alunos se dedicam individualmente, expressando-se por vezes em voz alta, à exploração (subconfiguração a-didática). O aluno Marcelo descobre, ao observar a sequência que representa o número de bolinhas em cada posição $(3,8,15$, $24 . .$.$) , que o número de bolinhas que são acrescidas de uma figura para outra (5,$ $7,9,11,13 \ldots$ ) aumenta de 2 em 2. Paulo discorda e Marcelo tenta convencer o colega através do procedimento de contagem.

Em um momento mais adiante (SCD9), o aluno Paulo requisita a atenção de Prof 2. Prof 2 faz uma série de perguntas tentando inteirar-se do trabalho desenvolvido (subconfiguração dialógica) e sugere ao grupo que pensem em uma relação entre a quantidade de pontos de cada figura e uma operação [301, 303, 309] (padrão de focalização). Com essa intervenção procurava incentivar a elaboração de uma expressão matemática que pudesse descrever o enésimo

\footnotetext{
${ }^{8}$ Os alunos, dentre outras coisas, verificaram: que o número de bolinhas acrescidas de uma figura para outra não se mantém; que na primeira linha cada figura tem o número de bolinhas correspondente à sua posição; que são acrescentados eles (L) na transformação de uma figura em outra.
} 
termo da sequência. Porém, os alunos permanecem sem conseguir progredir, como verificamos no extrato abaixo:

Prof 2: Como é que vocês estão fazendo isso aqui? Quantos pontinhos tem em cada figura? Vocês estão desenhando? Não pensaram em nenhuma operação para ver a quantidade de pontos? [301]

Todos: Não. [302]

Prof 2: Vocês acham que não tem uma operação... [303]

Marcelo: Ter uma operação tem! [304]

Paulo: A gente só não sabe... [305]

Prof 2: Vocês acham que não tem nenhuma conta que a gente pode relacionar aqui que vai dar esse tanto, aí depois a mesma que vai dar esse tanto? [309]

Marcelo: 4 x 2... 8. [311]

Paulo: acho que é adição professora. [312]

Marcelo: Não, tem outra coisa. [313]

Paulo: Pode ter alguma coisa a ver com o x. [314]

Prof 2: Que x? [315]

Paulo: Não sei. [316]

Prof 2: Humm... [317]

Os alunos seguem conferindo o número de bolinhas em cada posição (utilizam as tampinhas para construir as figuras) e Prof 2 passa a acompanhar,

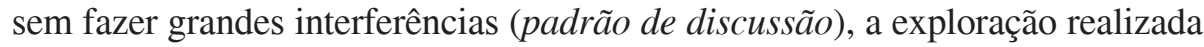
por eles.

Prof 2: A próxima figura vai ter quanto? [324]

Paulo: 35. [325]

Vanderlei: Não, a próxima figura não vai ter 35 não. Essa aqui é a $3^{\mathrm{a}}$. A $4^{\mathrm{a}} \ldots$... Aqui não pede a $4^{\mathrm{a}}$ não, pede a $5^{\mathrm{a}}$ já. A $5^{\mathrm{a}}$ é35. [326]

Prof 2: A $4^{\mathrm{a}}$ tem quanto? [327]

Paulo: Peraí, professora. [328]

Prof 2: Tá. [329]

Paulo: Então eu não fiz a $5^{\mathrm{a}}$. [330]

Prof 2: Então, peraí. Vamos partir desta, tá? Tem quantos na coluna? [331]

Paulo: A primeira? [332]

Prof 2: Vamos começar dessa. Tem 4 por 4. [333]

Paulo: Uma linha tem 3. [334]

Prof 2: Só a linha de cima que tem 3, não é? [335]

Paulo: É. [336] 
Segue-se uma discussão, mediada por Prof 2, com o intuito de levar os alunos a comprovar que os acréscimos de bolinhas de uma figura para outra não se mantêm [363, 365, 377, 399] e que, portanto, é infrutífero insistir nesse caminho [411]. Sugere, então, sutilmente, que os alunos relacionem o padrão da sequência com uma figura geométrica (padrão de focalização) [411]. O fato de faltar uma bolinha parece impedir, no entanto, que a figura possa ser pensada como quadrado.

Prof 2: Tá aumentando. Só que a regularidade de uma figura pra outra foi aumentando? [363]

Paulo: Não. [364]

Prof 2: Foi a mesma? [365]

Paulo: Não, peraí... [366]

Prof 2: Então olha só... Da primeira pra segunda aumentou quanto? [367]

Paulo: 5. [368]

Prof 2: Da $1^{\mathrm{a}}$ pra $2^{\mathrm{a}}$. Da $2^{\mathrm{a}}$ pra $3^{\mathrm{a}}$ ? [369]

Vanderlei: 7! [376]

Prof 2: 7. Então já não é o mesmo tanto... Cuidado com isso!

Da $3^{\mathrm{a}}$ pra $4^{\mathrm{a}}$ aumentou quanto? [377]

Prof 2: E da outra? Tá vendo que não é o mesmo tanto? De uma figura aumenta um tanto e de outra... [399]

Paulo: Não é a mesma regra![407]

Prof 2: E aí gente! Não era então o que vocês estavam pensando... Será que não tem nenhuma outra conta... Não estão lembrando nenhuma outra assim...figura?! [411]

Mais adiante, iniciando a SCD10, Prof 1, que havia sido informada por Prof 2 do fato de o grupo se encontrar paralisado, é levada a intervir de uma forma predominantemente magistral, ainda que também interagisse com os alunos (subconfiguração magistral interativa ${ }^{9}$ ). Prof 1 começa sua intervenção perguntando qual figura geométrica poderia ser identificada com cada uma das figuras da sequência [431]. Ainda que o aluno Paulo continue afirmando que se trata de quase um quadrado [433] e, mais adiante, que não parece um quadrado [435], Prof 1 ignora essas falas e segue perguntando se figuras em outras posições parecem um quadrado [434, 437], ao que Vanderlei responde afirmativamente [436, 438]. No turno 439, Prof 1 conclui a discussão, reformulando a fala de Vanderlei [436], e Paulo, a partir dessa validação, parece se convencer de que é possível considerar que cada figura da sequência se trata

\footnotetext{
${ }^{9}$ A denominação configuração magistral-interativa foi adotada em Pochulu e Font (2011).
} 
de um quadrado menos uma parte [443] ou um quebra-cabeça sem uma peça como definirá, logo a frente, Valter [456]. A interação que Prof 1 estabelece aproxima-se do monologismo ${ }^{10}$, já que opta por perguntas fechadas e específicas que requerem uma resposta convergente, aceitando como válidas apenas as respostas que considera corretas (padrão de recitação).

Prof 1: Essa figura parece o quê? O que que tá parecendo essa aqui, ó? [431]

Vanderlei: Um quadrado, só que tá faltando uma bolinha... [432]

Paulo: Quase um quadrado. [433]

Prof 1: Então? Como que a gente pode pensar então? Essa aqui parece um quadrado? [434]

Paulo: Não. [435]

Vanderlei: Parece. Só que tá faltando uma bolinha. [436]

Prof 1: Essa aqui parece um quadrado? [437]

Vanderlei: Parece. [438]

Prof 1: Então, qual é que vai ser o próximo termo? Um quadrado faltando um. [439]

Paulo: É um quadrado... Ahhhhhhhhhh.... (sorrindo) [441]

Prof 1: Então! Como é que é Paulo? [442]

Paulo: Seria um quadrado menos uma parte... [443]

Valter: É só pensar em um quebra-cabeça sem uma peça. [456]

Em um trabalho autônomo (SDC11) e a partir da compreensão de que cada figura poderia ser pensada como um quadrado faltando uma bolinha, Marcelo consegue progredir, verificando que o número de bolinhas em cada figura corresponde ao número de bolinhas da lateral vezes o número de bolinhas da base menos um (Figura 3). Marcelo testa sua descoberta [453, 455, 458], tentando convencer o aluno Paulo que sua ideia está correta. Prof 1 valida as falas de Marcelo [454, 464], diz a Paulo que a ideia do colega está correta [466] e pede a ele que teste o termo seguinte [466].

Marcelo faz um gesto traçando uma linha vertical imaginária sobre a primeira coluna e, em seguida, traçando uma linha horizontal sobre a primeira linha. Logo após, aponta para o espaço em branco onde deveria estar a bolinha que falta.

\footnotetext{
${ }^{10} \mathrm{O}$ monologismo pressupõe pensamentos, asserções e proposições que são consideradas verdadeiras ou falsas independente de quem os enuncia; ou seja, o conteúdo desses pensamentos não é afetado pela sua fonte nem requer a voz ou o contexto particular de sua produção (MORSON; EMERSON, 2008).
} 


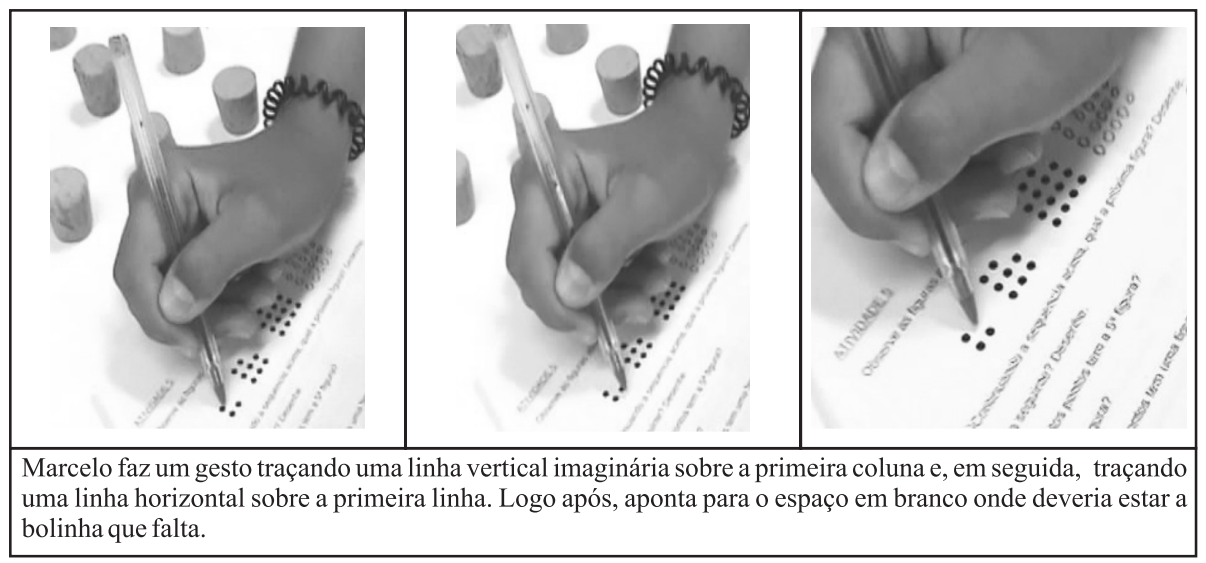

Figura 3 - Linguagem gestual de Marcelo

Fonte: dados da pesquisa

Marcelo: É 2 x 2, 4 - 1. [453]

Prof 1: Isso! Muito bem! [454]

Marcelo: É 3 x 3, 9 - 1. [455]

Valter: É só pensar em um quebra-cabeça sem uma peça. [456] (Marcelo dá uma gargalhada)

Paulo: Isso aí eu já sei que é menos 1. [457]

Marcelo: Mas essa que é a regra! Presta atenção: 4 x 4, 8 . Aqui tem 15, né? [458]

Paulo: 15. [459]

Marcelo: Ah, tá. 4 x 4, 16. 16 - 1, 15. [463]

Prof 1: 15! Aí a próxima figura seria... [464]

Paulo: Tá errado. [465]

Prof 1: Paulo, tá certinho. A próxima figura: 5 x 5? [466]

Paulo: 25 [467]

Prof 1: 25-1? [468]

Paulo: Então ela tem 24[469]

Em um momento final (SCD12), Prof 1, buscando garantir um trabalho com maior profundidade, chama a atenção do grupo para o fato de, na primeira posição, a base possuir duas bolinhas [474, 494] (subconfiguração magistral interativa). O grupo passa a acompanhar o desenvolvimento da ideia de que na base da figura há sempre uma bolinha a mais que a posição a que esta se refere e consegue responder corretamente o número de bolinhas existentes na base e o número de bolinhas total para a $10^{\mathrm{a}}$ posição [496] (padrão de recitação). 
Prof 1: Olhe uma coisa diferente que acontece. Na primeira figura... [474]

Prof 1: Peraí. Tipo assim: $1^{\mathrm{a}}$ posição, $2^{\mathrm{a}}$ posição, $3^{\mathrm{a}}$ posição... Beleza! Presta atenção aqui, gente! $\mathrm{Na} 1^{\mathrm{a}}$ posição tem 2 bolinhas. $\mathrm{Na} 2^{\mathrm{a}}$ posição tem 3 bolinhas... Na $3^{\mathrm{a}}$, tem 4 ! É sempre uma bolinha... [494]

Valter: A mais... [495]

Prof 1: Então pensem comigo. Na $10^{\mathrm{a}}$ posição, quantas bolinhas vamos ter? $\mathrm{Na} 10^{\mathrm{a}} \ldots$ [496]

Paulo: Vai ter 11! [497]

Prof 1: 11! Muito bem! Então vai ser 11... [498]

Valter: Vezes 11 menos um... [499]

Prof 1: 11 x 11 - 1 que fica faltando sempre... [500]

Na última subconfiguração didática da atividade 2 (SCD13), o grupo dedica-se ao registro escrito e trabalha sem a interferência das professoras (subconfiguração a-didática).

Prof 1 esperava que, com a regulação estabelecida por ela na SCD12, o grupo conseguisse expressar a regra de formação da sequência com uma expressão como posição mais um, vezes posição mais um, menos um ou até com uma expressão matemática como $(\mathrm{p}+1)^{2}-1$. Apesar de o grupo realizar o cálculo para o item $d$ da atividade 2 utilizando uma expressão matemática [515], não consegue atingir esse aprofundamento constando, para o item $e$ da tarefa, simplesmente a base por ela mesma e tira um ou a base pela lateral menos um.

Valter: E a 6 a figura? [509]

Vanderlei: Dá 49 e vai ter que tirar mais um, dá 48. Eu contei. [510]

Paulo: 48! [511]

Paulo: A6 ${ }^{\mathrm{a}}$ vai ter $7.7 \times$ X $7,49.49-1,48$ ! [515]

De maneira similar, na atividade 3 (Figura 2), os alunos não conseguiram obter uma regra geral para a sequência. Nos registros escritos consta a expressão: a base +1 . a lateral. Os alunos conseguiram concluir que o número de bolinhas na lateral da figura é o mesmo da posição que a mesma ocupa na sequência e que em sua base sempre vai ter uma bolinha a mais comparada à lateral. Esperava-se, no entanto, que conseguissem obter uma expressão matemática como, por exemplo, p. $(\mathrm{p}+1)$ ou $\mathrm{p}^{2}+\mathrm{p}$. Já na atividade 1, os alunos conseguiram alcançar a generalização obtendo a expressão $2 . x$ para o enésimo termo da sequência. 


\section{Discussão}

A análise da trajetória didática implementada, descrita no Quadro 2, permite-nos verificar a predominância das subconfigurações a-didáticas, seguidas das subconfigurações dialógicas - em que os padrões de focalização se fizeram necessários - e subconfigurações magistrais em que, embora se estabelecesse diálogo entre a professora e os alunos, é adotado um padrão de recitação.

Uma regularidade interessante a se observar nessa trajetória é a forma cíclica com que os padrões de interação se entrelaçam. As professoras, buscando otimizar a aprendizagem, inicialmente permitem que os alunos trabalhem sozinhos, em seguida intervêm de maneira dialógica e, por fim, ou novamente, permitem o trabalho independente ou tomam a decisão de agir de maneira magistral. Essas interações cíclicas, determinadas pelo gerenciamento da aprendizagem, são formatadas pela tomada de decisão das professoras frente a trajetória do pensamento matemático mobilizado pelos alunos.

Apesar dos padrões de interação estabelecidos pelas professoras e dos níveis de investigação adotados (níveis 2 e 3 do Quadro 1), o grupo só conseguiu expressar o enésimo termo, através de uma expressão matemática, na atividade 1 da tarefa, o que significa dizer que outros momentos de subconfiguração magistral interativa (ou no mínimo dialógica com estabelecimento de um padrão de focalização) se fariam necessários para que os alunos alcançassem êxito nas atividades 2 e 3 .

Não obstante a abordagem investigativa enfatize a importância de os alunos se engajarem na produção do próprio conhecimento de maneira autônoma, o que aconteceu de fato, como mostra nossa pesquisa, é que "a maioria dos alunos, independentemente da idade, precisam de ampla prática para desenvolver as suas capacidades de investigação e compreensão, a ponto de poderem conduzir sua própria investigação do início ao fim" (BANCHI; BELL, 2008, p. 26). Faz-se necessário, portanto, que o professor ofereça andaimes (scaffoldings) de maneira a tornar as tarefas acessíveis e manejáveis, visando à emergência de possíveis zonas de desenvolvimento proximal (ZDP), conforme concebidas por Meira e Lerman (2010), e ilustradas no contexto de um pesquisa interdisciplinar entre as disciplinas Matemática e Ciências realizada em uma turma do Ensino Fundamental por Frade e Meira (2012).

Frade e Meira (2012) discutem que, segundo Meira e Lerman (2010), o construto ZDP, introduzido por Vygotsky em sua formulação final, vincula-se a 
um espaço simbólico, de mediação semiótica que "vai além da situação sociointeracional imediata, enfocando mais o mundo mediado simbolicamente que permeia a situação ou as atividades de resolução de problemas" (FRADE; MEIRA, 2012, p. 374). Frade e Meira (2012) explicam que, para Meira e Lerman (2010), isso significa dizer três coisas principais: primeiro, uma ZDP não é espaço quase físico que cada aluno possui e que o professor precisa apenas descobrilo para tornar seu ensino bem-sucedido; ao contrário, uma ZDP é um fenômeno "que emerge (ou não) na instrução ou em interações dialógicas de qualquer natureza, dentro do qual ocorrem o cultivo social de processos ainda não desenvolvidos e a construção, pelos indivíduos, de estruturas futuras de suas funções intelectuais sob as bases de suas experiências passadas" (FRADE; MEIRA, 2012, p. 377). Segundo, ver uma ZDP como um espaço simbólico nos capacita a mudar o foco para além do indivíduo per se em direção à emergência de modos de comunicação. Terceiro, a ZDP é um espaço simbólico para interações e comunicações, no qual a aprendizagem conduz o desenvolvimento.

Diante do exposto acima, entendemos que os atos comunicativos (no sentido de reciprocidade que estamos utilizando aqui) gerados em sala de aula podem, então, criar condições para que funções intelectuais que estão em processo de amadurecimento (desenvolvimento iminente ${ }^{11}$ ), possam se revelar e tenham a possibilidade de amadurecerem. Assim, muito embora os padrões de focalização e recitativos estreitem o espaço de possibilidades ou comportamentos possíveis dos alunos, limitando o grau de trabalho independente, compreendemos que esse apoio é necessário, pois, de acordo com a concepção de ZDP que adotamos, pode ser componente fundamental para o processo de aprendizagem.

Apesar de o EOS apontar o trabalho autônomo dos estudantes (presumindo um nível mais alto de investigação), como um critério de idoneidade interacional $^{12}$, nossos dados e reflexões mostram que, no contexto aqui

\footnotetext{
${ }^{11} \mathrm{Na}$ tese elaborada por Prestes (2010, p. 173) o termo ZDP é substituído por Zona de Desenvolvimento Iminente. Com base na compreensão do termo russo zona blijaichego razvitia, a autora aponta as confusões nas traduções desse termo e discute os equívocos em sua interpretação. Prestes defende que a tradução que mais se aproxima do termo zona blijaichego razvitia é "zona de desenvolvimento iminente, pois sua característica essencial é a das possibilidades de desenvolvimento, mais do que do imediatismo e da obrigatoriedade de ocorrência, pois se a criança não tiver a possibilidade de contar com a colaboração de outra pessoa em determinados períodos de sua vida, poderá não amadurecer certas funções intelectuais e, mesmo tendo essa pessoa, isso não garante, por si só, o seu amadurecimento".

${ }^{12}$ A idoneidade interacional está sujeita, no entanto, a outras quatro, que em uma articulação coerente e sistêmica, definem a idoneidade didática de um processo de ensino e aprendizagem: idoneidade epistêmica, idoneidade cognitivo-afetiva, idoneidade mediacional e idoneidade ecológica (GODINO; BATANERO; FONT, 2008).
} 
considerado (alunos de aproximadamente 12 anos que não tinham tido, até então, contato com atividades investigativas), os alunos necessitam de grande apoio por parte do professor, já que apresentam dificuldade em progredirem quando trabalham sozinhos ou recebem uma orientação minimamente guiada.

Em outras palavras, se o professor não alterar a trajetória didática implementando de forma articulada configurações do tipo dialógicas e magistrais - a aprendizagem não alcançará o nível desejado. Tal fato nos remete à complexidade do trabalho do professor, que deve ter um conhecimento amplo das configurações epistêmicas de referência, das configurações cognitivas dos alunos em relação aos conteúdos matemáticos pretendidos, ser capaz de identificar em momentos críticos os conflitos semióticos ${ }^{13} \mathrm{e}$ tomar decisões sobre o tipo de atuação que deve adotar (GODINO et al., 2006).

De fato, não basta dispor de situações ricas ou criar um espaço para que os alunos expressem o que pensam, nem é suficiente avaliar suas ideias como certas ou erradas. É preciso que o professor questione e problematize as ideias dos alunos, gerenciando as distintas configurações e padrões de interação para estabilizar a negociação de significados e otimizar a aprendizagem.

\section{Conclusões}

Neste artigo, descrevemos os resultados da análise de uma experiência educativa, aplicando algumas noções teóricas do EOS. Esse modelo nos permitiu interpretar os dados de uma maneira sistemática e profunda e, em consequência, revelar um fenômeno didático associado à gestão do ensino e aprendizagem de Matemática, em um contexto de aulas exploratório-investigativas: a necessária cooperação produtiva (sinergia) entre os distintos padrões de interação com a finalidade de possibilitar o desenvolvimento da aprendizagem dos alunos. $\mathrm{O}$ desenvolvimento da aprendizagem matemática se pode otimizar, em determinadas circunstâncias, mediante uma estratégia metodológica mista em que o padrão de interação a-didático articula-se com outros padrões de trabalho cooperativo, dialógico e inclusive magistral. Essa articulação pode ser crucial para o desenvolvimento da aprendizagem dos alunos.

\footnotetext{
${ }^{13}$ Define-se como conflito semiótico qualquer disparidade ou discordância entre os significados atribuídos a uma expressão por dois sujeitos - pessoas ou instituições (GODINO, 2002).
} 


\section{Reconhecimento}

A contribuição de Adriana Assis realizou-se com subsídio de bolsa concedida pela Coordenação de Aperfeiçoamento de Pessoal de Nível Superior (CAPES) - Ministério da Educação do Brasil. A contribuição de Cristina Frade teve subsídio de auxílio concedido pelo Conselho Nacional de Desenvolvimento Científico e Tecnológico (CNPq). A contribuição de Juan. D. Godino foi parcialmente apoiada no marco do Projecto, EDU2010-14947, Ministério de Ciência e Inovação (MICINN).

\section{Referências}

ASSIS, A.; GODINO, J. D.; FRADE, C. As dimensões normativa e metanormativa em um contexto de aulas exploratório-investigativas. Revista Latinoamericana de Investigación en Matemática Educativa (RELIME), México, D.F., v. 15, n. 2, p. 171-198, jul. 2012.

BANCHI, H.; BELL, R. The many levels of inquiry. Science and Children, Virginia, v. 46, n. 2, p. 26-29, Oct. 2008.

BAUERSFELD, H. Interaction, construction, and knowledge: alternative perspectives for mathematics education. In: EFFECTIVE MATHEMATICS TEACHING (DIDACTICS OF MATHEMATICS) - TME-CONFERENCE, $2^{\text {nd }}$, 1988, Antwerp. Proccedings... Antwerp: University of Antwerp - COONY, T.; GROWS, D. (Ed.), 1988. p. 174-168. CD-ROM.

BOGDAN, R. C.; BIKLEN, S. K. Investigação qualitativa em educação. Porto: Porto Editora, 1994.

BRUNER, J. Atos de significação. Porto Alegre: Artmed, 2002.

D’AMORE, B.; FONT, V.; GODINO, J. D. La dimensión metadidáctica en los procesos de enseñanza y aprendizaje de las matemáticas. Paradigma, Maracay, Venezuela, v. 28, n. 2, p. 49-77, dec. 2007.

ERNEST, P. Varieties of constructivism: a framework for comparison. In: STEFFE, L.; NESHER, P.; COBB, P.; GOLDIN, G.; GREER, B. (Ed.). Theories of Mathematical Learning. Mahwah, New Jersey: Lawrence Erlbaum Associates, 1996. p. 335-350. 
FONT, V.; PLANAS, N.; GODINO, J. D. Modelo para el análisis didáctico en educación matemática. Infancia y Aprendizaje, Madrid, v. 33, n. 1, p. 89-105, feb. 2010.

FRADE, C.; MEIRA, L. Interdisciplinaridade na escola: subsídios para uma zona de desenvolvimento proximal como espaço simbólico. Educação em Revista, Belo Horizonte, v. 28, n. 1, p. 371-394, mar. 2012.

GODINO, J. D. Un enfoque ontológico y semiótico de la cognición matemática. Recherches en Didactiques des Mathematiques, Roubaix, v. 22, n. 2/3, p. 237-284, 2002.

GODINO, J. D.; BATANERO, C.; FONT, V. Um enfoque ontossemiótico do conhecimento e a instrução matemática. Acta Scientiae, Canoas, v. 10, n. 2, p. 7-37, jul./dez. 2008.

GODINO, J. D.; CONTRERAS, A.; FONT, V. Análisis de procesos de instrucción basado en el enfoque ontológico-semiótico de la cognición matemática. Recherches en Didactiques des Mathematiques, Roubaix, v. 26, n. 1, p. 39-88, 2006.

GODINO, J. D.; LLINARES, S. El interaccionismo simbólico en Educación Matemática. Revista Educación Matemática, México, D. F., v. 12, n. 1, p. 70-92, 2000.

GODINO, J. D.; ROA, R.; RECIO, A. M.; RUIZ, F.; PAREJA, J. L. Análisis didáctico de un proceso de estudio de la ley empírica de los grandes números. Revista Educação Matemática Pesquisa, São Paulo, v. 8, n. 2, p. 157-175, 2006.

HMELO-SILVER, C. E.; DUNCAN, R. G.; CHINN, C. A. Scaffolding and achievement in Problem-Based and inquiry learning: a response to Kirschner, Sweller, and Clark (2006). Educational Psychologist, Mahwah, v. 42, n. 2, p. 99-107, 2007.

MEIRA, L.; LERMAN, S. Zones of Proximal Development as fields for communication and dialogue. In: LIGHTFOOT, C.; LYRA, M. C. D. P. (Org.). Challenges and strategies for studying human development in cultural contexts. Rome: Information Age Pub Inc., 2010. p. 199-219.

MENEZES, L. Desenvolvimento da comunicação matemática em professores do $1^{\circ}$ ciclo no contexto de um projecto de investigação colaborativa. In: SIMPÓSIO INTERNACIONAL DE EDUCAÇÃO MATEMÁTICA(SIEM), 16., 2005, Setúbal. Actas do XVI SIEM... Setúbal: APM, 2005. p. 349-365. CD-ROM 
MORSON, G. S.; EMERSON, C. Mikhail Bakhtin: a criação de uma prosaística. São Paulo: Edusp, 2008.

PINO, A. O conceito de mediação semiótica em Vygotsky e seu papel na explicação do psiquismo humano. Educação e Sociedade, Campinas, n. 24, p. 32-43, mar. 1991.

PLANAS, N.; IRANZO, N. Consideraciones metodológicas para el análisis de procesos de interacción en el aula de matemáticas. Revista Latinoamericana de Investigación en Matemática Educativa (Relime), México, D.F., v. 12, n. 2, p. 179-213, jul. 2009.

POCHULU, M.; FONT, V. Análisis del funcionamiento de una clase de Matemáticas no significativa. Revista Latinoamericana de Investigación en Matemática Educativa (Relime), México, D.F., v. 14, n. 3, p. 361-394, nov. 2011.

PONTE, J. P.; FONSECA, H.; BRUNHEIRA, L. As atividades de investigação, o professor e a aula de Matemática. In: ASSOCIAÇÃO DOS PROFESSORES DE MATEMÁTICA, 1999, Lisboa. Actas do ProfMat99... Lisboa: APM, 1999. p. 91-101. CD-ROM.

PRESTES, Z. R. Quando não é quase a mesma coisa. Análise de traduções de Lev Semionovitch Vigotski no Brasil. Repercussões no campo educacional. 2010. 295 f. Tese (Doutorado em Educação) - Universidade de Brasília, Brasília, 2010.

SIERPINSKA, A. Whither mathematics education? In: CONGRESO INTERNATIONAL DE EDUCACIÓN MATEMÁTICA, 8., 1996, Sevilla. Actas ICME'8... Sevilla: Sociedad Thales/ ALSINA, C. et al. (Ed.), 1996. p. 21-46. CD-ROM.

SOUZA, E. R.; DINIZ, M. I. S. V. Álgebra: das variáveis às equações e funções. São Paulo: IME-USP, 2003. Coleção do CAEM - Centro de Aperfeiçoamento do Ensino da Matemática, Vol. 5.

STACEY, K. Finding and Using Patterns in Linear Generalising Problems. Educational Studies in Mathematics, Netherlands, v. 20, n. 2, p. 147-164, 1989.

VOIGT, J. Patterns and routines in classroom interaction. Recherches en Didactique des Mathématiques, Roubaix, v. 6, n. 1, p. 69-118, 1985.

VOIGT, J. Thematic patterns of interaction and sociomathematical norms. In: COBB, P.; BAUERSFELD, H. (Ed.) The emergence of mathematical meaning: interaction in classroom cultures. New Jersey: Hillsdale, 1995. p. 163-199. 
VOIGT, J. Negotiation of mathematical meaning in classroom processes: Social interaction and learning mathematics. In: STEFFE, L. et al. (Ed.). Theories of Mathematical Learning. Mahwah: Lawrence Erlbaum Ass. Pub., 1996. p. 21-50.

WOOD, T. Patterns of interaction and the culture of the mathematics classroom. In: LERMAN, S. (Ed.). Culture Perspectives on the Mathematics Classroon. Dordrecht: Kluwer Academic Publ., 1994. p. 149-168.

Submetido em Agosto de 2012. Aprovado em Novembro de 2012. 